\title{
Evaluation of Antibacterial Effects of Polyurethane- Cinnamomum zeylanicum Nanofiber Scaffolds against Clinical Isolates of Staphylococcus aureus
}

Hoorieh Hoseinpoor (MSc) Department of Microbiology and Applied Microbiology Research Center, Systems Biology and Poisonings Institute and Applied Virology Research Center, Baqiyatallah University of Medical Sciences, Tehran, Iran

Davoud Esmaeili (PhD)

Department of Microbiology and Applied Microbiology Research Center, Systems biology and poisonings institute and Applied Virology Research Center, Baqiyatallah University of Medical sciences, Tehran, Iran

Corresponding author: Davoud Esmaeili

Email: esm114@gmail.com Tel: +982182883422

Address: Baqiyatallah University of Medical sciences, Nosrati Alley,

Sheikh Bahai South Avenue, Mollasadra St. Vanak Sa. Tehran. Iran

Received: 03 Mar 2018

Revised: 02 Feb 2018

Accepted: 28 Feb 2018

\section{(c) (i) (9)}

This work is licensed under a Creative Commons Attribution 4.0 License.
ABSTRACT

Background and Objectives: In recent years, infections caused by antibioticresistant strains of Staphylococcus aureus have become a major health issue. It has been suggested that the extract or essential oil of cinnamon tree has antibacterial properties. In this study, we investigated the antibacterial effects of polyurethane-cinnamon nanofibers against clinical isolates of $S$. aureus.

Methods: Polyurethane-Cinnamomum zeylanicum nanofiber scaffolds were synthesized. Polyurethane nanofiber and cinnamon polymers were also used to prepare the scaffold under the electrospinning process. Infrared spectroscopy, electron microscopy and mechanical tensile test were utilized to assess the scaffolds. Minimum inhibitory concentration of the nanofiber against the bacteria was determined using the broth dilution method according to the Clinical \& Laboratory Standards Institute guidelines.

Results: The results of antibiogram test showed that all tested disks were susceptible to $S$. aureus. Diameter of growth inhibition zone for polyurethane-cinnamon $10 \%$ was $41 \mathrm{~mm}$. Minimum inhibitory concentration of the nanofiber against $S$. aureus isolates was 0.02 $\mu \mathrm{g} / \mathrm{mL}$.

Conclusion: We demonstrated that the polyurethane-cinnamon nanofiber has favorable antibacterial effects against clinical isolates of $S$. aureus. It is recommended to conduct further studies on the antibacterial effects of this nanoiber on other bacteria.

Keywords: Staphylococcus aureus, Cinnamon, Nano fiber.

This paper should be cited as: Hoseinpoor $H$, Esmaeili $D$ [Evaluation of Antibacterial Effects of PolyurethaneCinnamomum zeylanicum Nanofiber Scaffolds against Clinical Isolates of Staphylococcus aureus]. mljgoums. 2019; 13(3):11-13 


\section{INTRODUCTION}

Staphylococcus aureus is a normal flora of the nose, skin and digestive tract of some people. The bacterium causes various infections ranging from simple skin infections to life-threatening diseases, such as pneumonia, meningitis, endocarditis, toxic shock syndrome and septicemia. It is also one of the main causes of nosocomial infections, especially post-surgical ulcers. It is estimated that 500,000 people in American hospitals become infected with $S$. aureus every year (1). Various factors including hemolysines, surface antigens, exotoxins, exogenous enzymes, siderophore and staphylogensin are involved in virulence of this bacterium (2). PantonValentine leukocidin is an important virulence factor in almost all methicillin-resistant $S$. aureus strains, which plays a role in the spread of cutaneous infections by eliminating leukocytes (3).

Currently, over $90 \%$ of S. aureus strains are resistant to penicillin, and resistance of these strains to semi-synthetic penicillins (methicillin, Nafcillin and oxacillin) is also increasing. Other antibiotics used for treatment of $S$. aureus infections include penicillin-like drugs such as carbapenems, sulbactam, cephalosporins and amoxicillin-clavulanic acid.

Medicinal herbs have various advantages over the chemical drugs namely less side effects, fewer risk of environmental pollution and widespread availability (4). Many studies have investigated the antibacterial activity of medicinal plants against various bacteria. In this study, we evaluated the inhibitory properties of polyurethane-Cinnamomum zeylanicum nanofiber scaffolds against $S$. aureus using the Kirby-Bauer test.

\section{MATERIALS AND METHODS}

Design and construction of nanoscaffolds consisted of two steps: solution preparation and setting up of an electrical apparatus. Fourier-transform infrared spectroscopy was used to evaluate the scaffold's structure. Tensile testing was done to examine the tensile strength and scanning electron microscope (SEM) was used to assess the morphology and topography of the scaffold. Twenty clinical isolates of $S$. aureus were obtained from the Baqiyatallah hospital in Tehran, Iran. Susceptibility of the isolates to the polyurethane-Cinnamomum zeylanicum nanofiber was assessed using the Kirby-Bauer test. S. aureus isolates were identified using catalase, coagulase, mannitol salt agar, production of deoxyribonuclease enzyme and bacitracin tests and sensitivity to novobiocin. After isolating the bacteria, a number of colonies was taken using a sterile loop and dissolved in sterile physiological serum. Turbidity was adjusted at 0.5 McFarland standard. Then, a homogenous solution was prepared and transferred on cation adjusted Muller Hinton agar. PolyurethaneCinnamomum zeylanicum nanofiber disks were placed on the Muller Hinton agar and the plate was incubated at $37{ }^{\circ} \mathrm{C}$ for 24 hours. Minimal inhibitory concentration (MIC) of polyurethane-Cinnamomum zeylanicum nanofiber against $S$. aureus was determined using the broth dilution method according to the Clinical \& Laboratory Standards Institute guidelines at concentrations of $0.01,0.02$, $0.03,0.04$ and $0.05 \mu \mathrm{g} / \mathrm{mL}$ (5).

\section{RESULTS}

In the Kirby-Bauer test, all strains were sensitive to the polyurethane-Cinnamomum zeylanicum nanofiber. Young's results show that by adding a polyurethane-darchine to a scaffold during electronics, it causes a slight decrease in tension and also a reduction in the Young's modulus (Table 1).

The diameter of growth inhibition around the disks was $41 \mathrm{~mm}$ (Table 2) and MIC of the nanofiber was $0.02 \mu \mathrm{g} / \mathrm{mL}$ against $S$. aureus isolates. Mechanical tensile test was carried out to examine the mechanical properties (tensile strength) of the scaffold. The elasticity of the scaffold of polyurethane nanofiber alone and in combination with the cinnamon essential oil was $3.94 \%$ and $0.096 \%$, respectively, indicating a linear deformation of the scaffold (Figure 1).

Table1- Results obtained from the Young's modulus

\begin{tabular}{|c|c|c|c|c|}
\hline Sample & $\begin{array}{l}\text { Width } \\
(\mathrm{mm})\end{array}$ & Thickness (mm) & Gage length $(\mathrm{mm})$ & Young's modulus \\
\hline Polyurethane & 10 & 0.066 & 20 & $0.752 \pm 0.02$ \\
\hline $\begin{array}{l}\text { Polyurethane + } \\
\text { Cinnamon }\end{array}$ & 10 & 0.035 & 20 & $0.096 \pm 0.01$ \\
\hline
\end{tabular}


Table 2- The diameter of the fibers using Image J software

\begin{tabular}{ccc}
\hline Group & Average $(\mathrm{mm})$ & Standard deviation \\
\hline Polyurethane & $\mathbf{0 . 5 8 9 2}$ & $\mathbf{0 . 4 7 0}$ \\
Polyurethane + Cinnamon & $\mathbf{0 . 9 1 0} \pm \mathbf{0 . 2 6 7}$ & $\mathbf{0 . 6 9 9} \pm \mathbf{0 . 2 4 1}$ \\
\hline
\end{tabular}

Figure 1- Results of the tensile test. A: Control scalfold, B: electrospun polyuvertan-cinnamon scalfold.
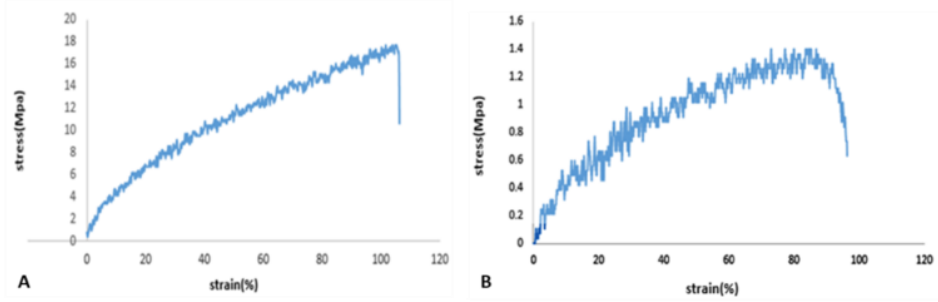

\section{DISCUSSION}

Currently, excessive use of antibiotics is among the main causes of increased rate of drug resistance (5). Infections caused by $S$. aureus may have serious health consequences, which requires effective and efficient treatment methods (6). The extract or essential oil of cinnamon tree contains bioactive ingredients including cinnamaldehyde, which has antibacterial properties. This is study was the first to investigate the inhibitory effects of polyurethane-cinnamon nanofibers on $S$. aureus. S. aureus can cause various infections in humans ranging from superficial skin lesions (boils and furuncle) to life-threatening infections such as pneumonia, meningitis and endocarditis. It is also one of the most important causes of nosocomial infections, especially via surgical wounds or medical equipment. Community acquired-methicillinresistant $S$. aureus can colonized in the host and evade the immune response with the help of its virulence factors (7-9).

\section{REFERENCES}

1. Boucher HW, Corey GR. Epidemiology of methicillinresistant Staphylococcus aureus. Clin Infect Dis. 2008; 46 Suppl 5: S344-9. doi: 10.1086/533590.

2. Meskini M, Khaledi A, Esmaeili D. Inhibitory Effects of a Herbal Ointment against Pseudomonas aeruginosa. mljgoums. 2019; 13(1): 1-5. DOI: 10.29252/mlj.13.1.1.

3. Rashki M, Ataee A, Alishiri G, Esmaeili D. Molecular Assay of Staphylococcal Enterotoxin E in Synovial Fluid of Patients with Rheumatoid Arthritis. Int J Infect. 2018; e14230. doi: 10.5812/iji. 14230

4. Argudín MÁ, Mendoza MC, Rodicio MR. Food poisoning and staphylococcus aureus enterotoxins. Toxins (Basel). 2010; 2(7): 1751-73. doi: 10.3390/toxins2071751.

5. Abbasi A, Bahador A, Esmaeili D, Mahbubi A, Amiri M, Amiri M. The Study of Inhibitory Effects of Satureja khuzestanica against MDR Isolates of Pseudomonas aeruginosa. International J of Current Microbiology and Applied Sciences. 2014; 2(3): 614-8.

\section{CONCLUSION}

Given the favorable results obtained in our study, the electrolytic polyurethanecinnamon nanofiber can be suggested as a potential antibacterial agent for the treatment of infections caused by $S$. aureus.

\section{ACKNOWLEDGEMENTS}

We would like to thank all participants in the study and staff of the Baqiyatallah hospital.

\section{CONFLICT OF INTEREST}

The authors declare that there is no conflict of interest.

\section{FUNDING/SUPPORT}

This research has been supported by the Baqiyatallah University of Medical Sciences, Iran.

6. Chihara S, Popovich KJ, Weinstein RA, Hota B. Staphylococcus aureus bacteriuria as a prognosticator for outcome of staphylococcus aureus bacteremia: a case-control study. BMC Infect Dis. 2010; 10: 225. doi: 10.1186/1471-2334$10-225$.

7. Garibaldi J. Media for the enhancement of fluorescent pigment production by Pseudomonas species. J Bacteriol. 1967; 94(5): 1296-9.

8. Hosseini MJ, Khaledi A, Daymad F, Esmaeili D. Evaluation of The Relationship Between class 1 Integrons and Drug Resistance Genes in Clinical Isolates of Pseudomonas aeruginosa. Open Microbiol J. 2016; 10: 188-96. doi: 10.2174/1874285801610010188.

9. Kiedrowski MR1, Horswill AR. New approaches for treating staphylococcal biofilm infections. Ann N Y Acad Sci. 2011; 1241: 104-21. doi: 10.1111/j.1749-6632.2011.06281.x. 